\title{
Thematic portal Znameniti.hr
}

\author{
Kristijan Crnković \\ ArhivPRO Ltd. \\ Proljetna 45, Koprivnica, Croatia \\ kristijan.crnkovic@arhivpro.hr \\ Vedrana Juričić \\ Croatian Academy of Sciences and Arts \\ Trg Nikole Šubića Zrinskog 11, Zagreb, Croatia \\ vea@hazu.hr \\ Irina Starčević Stančić \\ The Miroslav Krleža Institute of Lexicography \\ Frankopanska 26, Zagreb, Croatia \\ irinas@1zmk.hr
}

\section{Summary}

The digital infrastructure in Croatia is still waiting for a stronger investment cycle. Its development needs standardization and closer cooperation of all digital environment stakeholders. The work on the development of the thematic portal Znameniti.hr showed that these assumptions indeed are necessary preconditions. One-off financial support was provided by the Adris Foundation in 2016 within the project that was registered under the title Distinguished and Worthy Croats. The issue of standardization of data collection processing has finally started and an agreement has been reached that the name authority records from the National and University Library in Zagreb's digital repository should be used for building of the portal. Three unique set of metadata that will be applied for the bibliographic description of manuscripts, books, and collections of materials on the portal are also developed. Up until today, it has not been the case in Croatia that the materials are processed by standardized sets of metadata. Instead, institutions are applying their own descriptive elements. For all that, we believe that work on this project has spontaneously shifted the value of digital infrastructure in Croatia.

Key words: portal, distinguished and worthy Croats, Library of Croatian Academy of Sciences and Arts, collecting digital records, aggregation

\section{About thematic portal Znameniti.hr}

First of all, one-off financial support was provided by the Adris Foundation in 2016 within the project that was registered under the title Distinguished and 
Worthy Croats ${ }^{1}$. The portal Znameniti.hr was launched in 2016 by the Croatian Academy of Sciences and Arts, its Library as a coordinator, together with the National and University Library in Zagreb, the Zagreb City Libraries, and the State Archive in Varaždin. In the second phase of building the portal, other institutions, which have online collections and/or repositories with valuable materials on distinguished and worthy persons from the Croatian history and present, joined the project. Those are the Miroslav Krleža Institute of Lexicography, the Institute of Ethnology and Folklore Research, and the Museum of Arts and Crafts in Zagreb.

The project's objective is to establish a basis for collecting and consolidated search of metadata of Croatian cultural, artistic and scientific institutions' digital materials by building the portal Znameniti.hr containing digital materials on the champions of Croatian culture, science, arts, and public life from different collections and/or repositories. The purpose of the project is to enable better accessibility and use of non-commercial scientific, cultural and artistic digital content to researchers and wider public.

One of the main project tasks was to define the content framework and scope of the portal. The first step was to define the distinguished and worthy Croats. They are persons who worked in Croatia or outside Croatia, regardless of their origin or birth, or persons who contributed to the recognition, definition and affirmation of the Croatian identity by their actions and whose works became an important part of the Croatian heritage. According to this broad definition it was decided that the portal's title will be Znameniti.hr (eng. Distinguished.hr) (Figure 1). What was achieved by this? First of all, the name was shortened and made more memorable. The diacritical signs were avoided since they can cause different renderings on the computer screen, i.e. on the Internet. And finally, the national affiliation was removed from the portal's title itself allowing for future internationalization of the content.

Namely, thematic portal Znameniti.hr should be the beginning of the "little Croatian Europeana". Europeana, the largest digital platform in Europe, has been developing for ten years on the principles and standards that are related and applied to the portal Znameniti.hr. At the end of 2015 the Europeana portal, with its subtitle Think Culture, has been redesigned and renamed to Europeana Collections. The internet address has also been changed from http://www. europeana.eu to $\mathrm{https} / / / \mathrm{www}$.europeana.eu/portal $/ \mathrm{hr}$. At that time the first two collections appeared at the homepage - Art and Music. Today there are also collections Fashion, Photography, 1914-1918, Maps and Geography, Natural

\footnotetext{
${ }^{1}$ Inspiration for the project title was found in the renowned book Znameniti i zaslužni Hrvati te pomena vrijedna lica u hrvatskoj povijesti od 925-1925. (eng. The distinguished and worthy Croats and the persons worth mentioning from the Croatian history from 925 to 1925) published in Zagreb in 1925. (reprinted in Zagreb in 1990).
} 
K. Crnković, V. Juričić, I. Starčević Stančić, Thematic portal Znameniti.hr

History and Sport. One day, we hope, there will be a Distinguished Europeans portal.

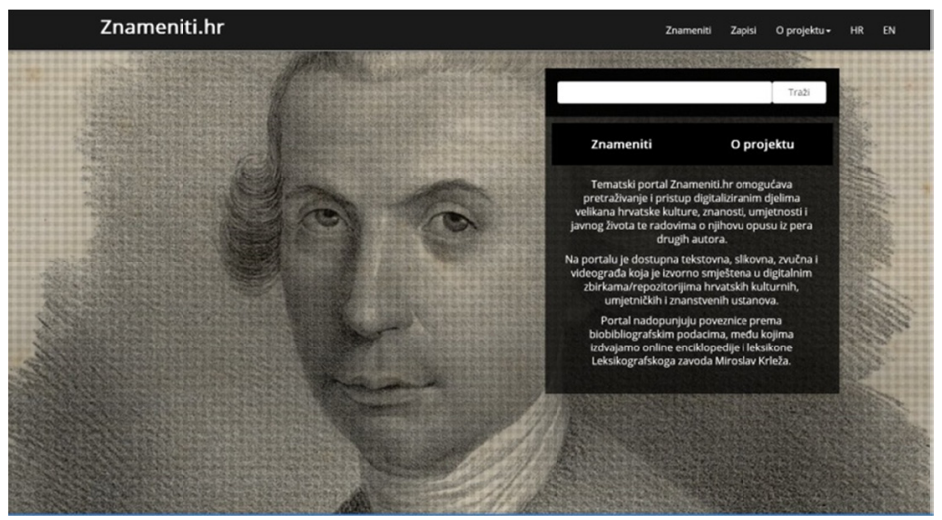

Figure 1. Homepage of thematic portal Znameniti.hr

\section{Selection criteria}

In this section, the main criteria for determining the process of publishing records of the distinguished persons will be discussed. It is important to determine the criteria and the possibilities for regular publication, e.g. one of the criteria may be a person's anniversary. During this process the rules for collection and presentation of digital data are determined.

Criteria for selecting the distinguished persons were: a) all persons who have a milestone anniversary of birth or death in the current year; b) all persons who already have a notable collection of digitised materials; c) special attention will be paid to the distinguished women; d) all persons with 10 or more digitised objects will be considered. Two data bases, the Croatian Encyclopaedia by The Miroslav Krleža Institute of Lexicography and the Zagreb City Libraries' Calendar of annual events were chosen as basis for collecting information on the distinguished persons. After collection, in the next step, distinguished persons who celebrate an anniversary between 2017 and 2020 were selected by applying the provenance criteria. Based on the current records a spreadsheet was created containing list of all distinguished persons and number of digital objects (texts, images, audio and video materials) available in the digital collections and/or repositories (Figure 2). It showed that some persons does not have a digital presence at all.

For example, it came as a surprise that only a few digital documents were created about Faust Vrančić whose 400th death anniversary is celebrating in 2017. In the same anniversary category for 2017 are Dobriša Cesarić, Gustav Krklec, Vesna Parun, Ivan Lukačić, Franjo Tuđman, Maksimilijan Vrhovac, Cardinal 
Franjo Kuharić, etc. On the other hand, there are many digitised materials about Vinko Žganec ${ }^{2}$, a well-known Croatian ethnomusicologist.

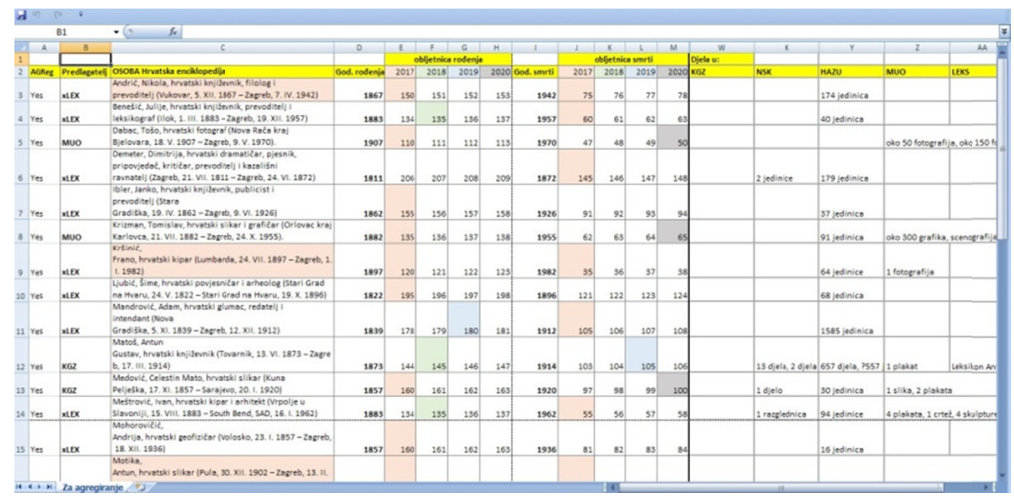

Figure 2. Spreadsheet containing list of all distinguished persons

\section{Metadata collection}

During the first project meeting in January 2017 it was decided that the process of collecting metadata will be performed as follows: in the repository of a participating institution, the digitized objects having a particular person as the author or the subject, will be selected, with all metadata included. Those records, when filtered, will be entered in the Znameniti.hr portal. Filtered metadata are merged at the OAI-PMH level, and are displayed at the portal interface.
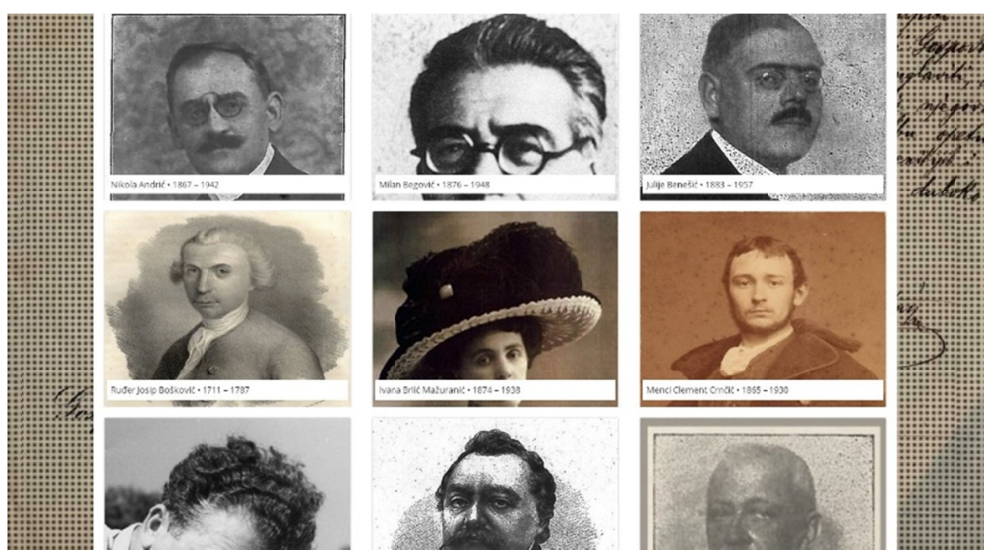

Figure 3. Photographs of the distinguished persons

\footnotetext{
${ }^{2}$ Around 60 CDs and around 80 collections were digitized. The collection of 40 photographs with dr. Žganec and 342 photograph mentioning Žganec in the title still remain to be digitized.
} 
K. Crnković, V. Juričić, I. Starčević Stančić, Thematic portal Znameniti.hr

An agreement was made to enrich the name authority records with ISNI and VIAF numbers - international standard identifiers. This is the criterion for aligning the identifiers of the name authority records. Local identifiers from each repository have been replaced by a global standard identifier that is unique in all repositories from which the data are selected. This solution has enabled the aggregation of heterogeneous data from different repositories and their integration into the portal Znameniti.hr. Consequently, the portal became the first aggregator portal to combine records created according to different metadata profiles from different institutions whose repository records are downloaded by the OAI-PMH protocol.

We have used the knowledge and technology that ArhivPRO Ltd. implemented in the aggregation system launched by the Ministry of Culture in 2013. This portal showed how important it is to develop an aggregate system that collects data from different digital sources.

\section{Search and retrieval}

The Znameniti.hr portal is created for wide-range of users (students, scientists, researchers) so it should be simple, incorporating well-designed search engine and instructions on how to navigate it. The photographs of distinguished persons, which follow immediately after the home page and offer the ability to browse through the content of the portal (Figure 3), are put forward. The portal provides search by different sets of metadata. The search results are displayed in two columns. In the left column, they are arranged in two groups of facets: Izvor zapisa (source record, i.e. institutions in whose repositories the requested data are stored), and Znameniti (list of distinguished persons whose works are included in the portal). The digitized objects are displayed in the right column. The structure of the portal Znameniti.hr and instructions for its use are shown in Figure 4.

URI (Uniform Resource Identifier), defined as a unique identifier of various sources on the Internet, has been identified as a prerequisite for acquiring the Croatian digital resources (URI HR). By using such identifier each resource can be uniquely identified and accessed.

The development of the portal Znameniti.hr also showed that the existing aggregating system, developed four years ago for aggregation of data for the Europeana, needs to be upgraded. Besides the name authority records data base, there is a lack of services for integration and unified search of other authoritative records. The idea of developing the Croatian Europeana, initially formulated in parallel with the development of the aggregating system but for different reasons still unrealised, now seems within reach by the development of the cooperation portal.

In the beginning, all the data and the portal application were hosted at the server of the company responsible for the application development (http://znameniti. eindigo.net). Later, the portal has been successfully moved to the virtual private 
server (VPS) allocated by the University Computing Centre (SRCE) to the Institute of Ethnology and Folklore Research. The allocated VPS space is shared with the DARIAH-HR consortium of institutions coordinated by the Institute. The Ministry of Culture of the Republic of Croatia has approved the use of the domain Znameniti.hr without fee. Thanks to that, http://znameniti.hr will be the permanent URL of the portal.

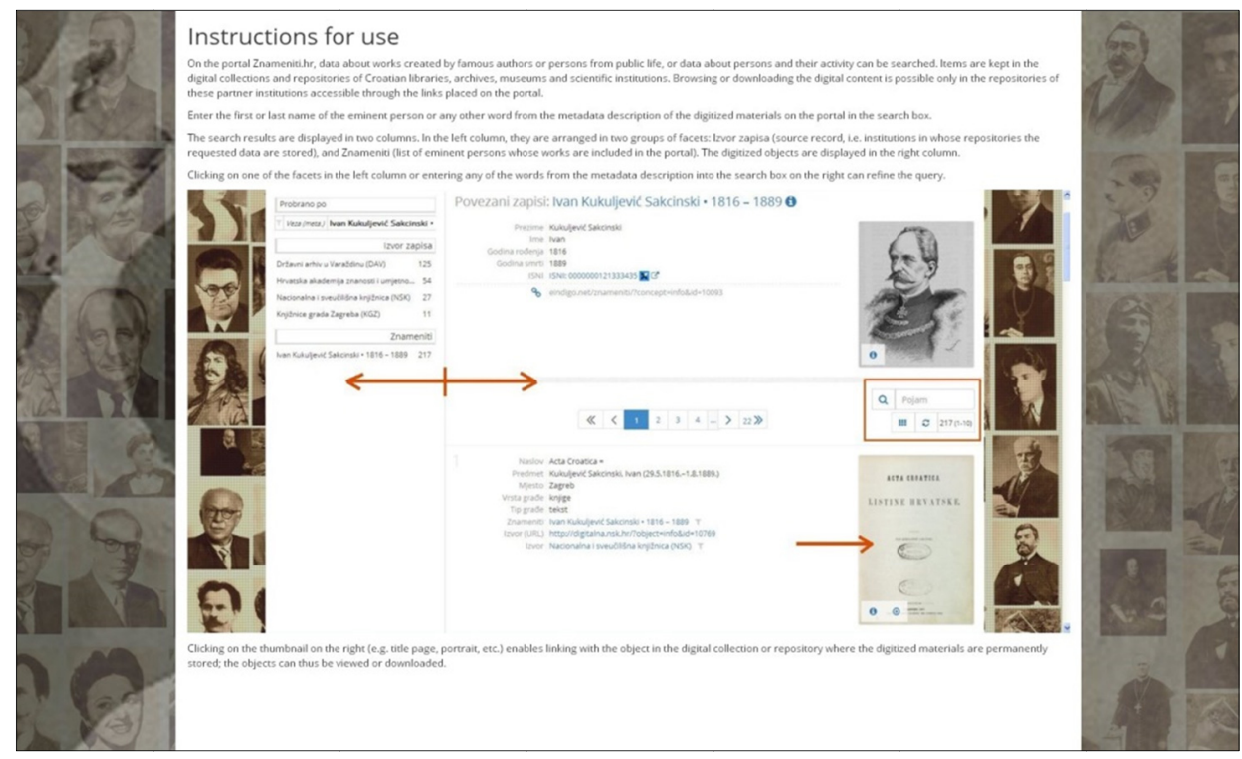

Figure 4. Instructions for use

\section{Conclusion}

The project Znameniti.hr, defined as a pilot project, aspires to become a unique access point for all digitized and/or digital objects on the distinguished persons originally placed in the digital collections and/or repositories of the MLA, scientific, and other institutions. The main precondition for developing this kind of portal is the existence of digital resources with accompanying metadata. This can facilitate the retrieval and provide a unified approach to all digital resources.

Currently in Croatia there is relatively modest number of repositories and they are not interconnected. There are also digital materials that are not preserved in an adequate manner and are not published on Internet, therefore not publically available. Croatia does not have its own, national, digital library. Because of that, it may be believed that the portal Znameniti.hr will draw attention to the need for development of the digital infrastructure in culture and science and initiate systematic metadata collection of the related records. Collecting the related records will allow their organization on a unique portal (e.g. Znameniti.hr) where they can be mutually connected and searchable. 
K. Crnković, V. Juričić, I. Starčević Stančić, Thematic portal Znameniti.hr

The main goals of the project Distinguished and Worthy Croats, as it was originally called, were significantly exceeded. The planned number of collected records, initially set to cca. 1,500 , was by the end of the first phase of project exceeded by $4 \frac{1}{2}$ times (the total of 35 distinguished persons with 6,511 records were collected). It is expected that the number of participating cultural and scientific institutions will grow as well as the number of included digital records on the distinguished persons. In the beginning of the project, four institutions were involved, but now four more institutions are showing their interest in collaboration and systematic collecting, publishing and interlinking of digital resources. That is why it was agreed that the cooperation of these eight institutions will continue, that the selected representatives from those institutions will form a coordination committee, and to define the cooperation through a special agreement.

Other institutions, having similar digital records, are also showing interest to contribute to the Znameniti.hr portal. In the initial phase, the cooperation may be realized by connecting the thematically organized metadata, e.g. music, film, art, history etc. This might be the foundation for development of the national cultural digital infrastructure, e.g. a national digital library. This portal is a great example in the still developing digital humanities area showing how digital materials, when processed by the cultural institutions, can become an important resource for education and science usable in the curriculum.

\section{Resources}

ArhivPRO Ltd., http://www.arhivpro.hr

Croatian Academy of Sciences and Arts, http://www.hazu.hr

Europeana portal, https://www.europeana.eu/portal/hr

Indigo - hybrid repository platform based on semantic technologies, http://www.eindigo.net/

National and University Library in Zagreb, http://www.nsk.hr

The Institute of Ethnology and Folklore Research, http://www.ief.hr

The Miroslav Krleža Institute of Lexicography, http://www.lzmk.hr

The Museum of Arts and Crafts in Zagreb, https://www.muo.hr/

The State Archive in Varaždin, http://www.dav.hr

The Zagreb City Libraries, http://www.kgz.hr 